\title{
A INFLUÊNCIA DO ALONGAMENTO ESTÁTICO APLICADO A FORÇA NO DESPOSTO: UMA REVISÃO LITERÁRIA
}

\section{Mario Vinicius de Andrade Vitório' \\ Shirley Ferreira Campos ${ }^{2}$ \\ Márcio Rodrigues de Matos $^{3}$}

\begin{abstract}
Resumo: Com o aumento dos investimentos em esportes, mais se discute sobre técnicas que visam otimizar o rendimento no desporto, dentre elas o alongamento. Salva-se que a variabilidade de aplicação das técnicas podem influenciar nos resultados esperados. Metodologia: Foi realizada revisão sistêmica literária, incluindo ensaios clínicos, artigos e livros publicados em datas compreendidas de 2005 a 2015 , incluindo as bases de dados eletrônicos PubMed, Science Direct, Scielo e PEDro. Resultados: O êxito do alongamento estático está relacionado ao tipo de protocolo utilizado ante a atividade, considerando que o fator tempo e intensidade podem ou não alterar os níveis de força muscular. Conclusão: A partir deste, estabelece que não há efeitos deletérios de desempenho para protocolos de alongamento estático de baixa intensidade e curta duração, entretanto, protocolos que apresentam maiores intensidades e tempos de duração, propiciam redução na força muscular.

Palavras-chave: Alongamento estático; Pré-exercício; Efeito; Agudo; Força máxima.
\end{abstract}

\footnotetext{
${ }^{1}$ Graduando em fisioterapia pela Universidade Paulista (UNIP), Brasil. E-mail: mariovitorio@outlook.com, ${ }^{2}$ Graduando em fisioterapia pela Universidade Paulista (UNIP), Brasil. E-mail: shirleycampos30@hotmail.com, ${ }^{3}$ Mestre em engenharia biomédica pela Universidade do Vale do Paraíba (UNIVAP), Brasil. E-mail: marciomatos_fisio@yahoo.com.br.
} 